\title{
JORGE, Lídia. O organista/The organist. Edição bilíngue. Alfragide: D. Quixote, 2014. 43 p.
}

O homem e a mulher empenhados em acabar com a monotonia do vazio criaram, com a ajuda do órgão, um conjunto harmónico de sons musicais e corais. Salpicaram essa sonoridade com uma pitada de sensualidade perspetivando, desse modo, uma multiplicação de sons e seres que ocupariam todo o vazio inicial. Esta magnífica criatividade de aparência demiúrgica foi então interrompida pelo Criador, "o pai de nada e de tudo" (JORGE, 2014, p. 17) que, admirado com o acontecimento, resolveu imiscuir-se no assunto, pois assiste-lhe o direito divino de atentar nas criações das suas criaturas, não vá o diabo tecê-las e essas criações ultrapassarem a sua própria. Agradavelmente surpreendido com aquela harmonia musical e felicidade sedutora, quis ele próprio participar delas experimentando o órgão. Mas, mau grado o Criador se ter feito criatura para tocar o órgão, o impulso sonoro que lhe imprimiu com o seu divino polegar, atingiu uma intensidade condigna do organista supremo, transformando-se num ato simultaneamente arrasador da criação existente, incluindo o homem e a mulher, e recriador de um novo universo, em que o ser humano só ressurgirá decorridos milhões de anos, seguindo um modelo evolucionista iniciado no protozoário.

$\mathrm{Na}$ sua aparente singeleza esta efabulação convidanos subtilmente para uma reflexão sobre o Homem criado por Deus e Deus criado pelo Homem, numa permanente busca um do outro, em encontros e desencontros que oscilam entre o mútuo fascínio e o recíproco desencanto. São as grandes interrogações e inquietações de ordem ontológica, antropológica e teológica que o Homem arrasta com a sua penosa existência no Universo, tratadas com um toque de humor. Impele-nos também o texto a uma reflexão sobre a cosmogénese ficcionada na ocorrência resultante da inesperada intervenção do Criador, cuja omnipotência não permitiu a realização de uma obra menor do que a recriação do Mundo. Todavia, a criação humana, ainda que com as limitações da espécie, o que apenas lhe confere um grau menor na escala demiúrgica, (pois o homem ao criar é ele também um demiurgo, um participante da obra de um deus maior) apresenta-se-nos valorizada relativamente à divina, porque esta, na sua obscena ilimitação, envolveu um processo regressivo de destruição, uma escatologia, tendo-se perdido todo o esforço que a humana espécie investira na sua própria evolução, todo o "a priori cultural" (CARVALHO, 2007, p. 49) se esvaneceu num ápice, pois a cultura é uma construção em permanência. O próprio Criador se achou desgostoso e "sentiu vergonha da natureza do seu criado" (JORGE, 2014, p. 41). Por seu lado, o homem e a mulher, em perfeita união entre si e com a arte, estavam conseguindo transformar a monotonia do vazio, porventura imagem do vazio existencial ou do vazio do futuro..., numa nova realidade, um novo mundo, repetindo, como deuses menores, o ato cosmogónico atribuído ao Criador. Deus criara o "todo" (ibidem, p. 19) e esse todo apresentava insuficiências que os humanos tentaram colmatar criando algo particularizado e que decorria em harmoniosa perfeição. Era, porém, expetável a intromissão de Deus ou o Criador, pois Ele e o Homem buscam-se em permanência, ainda que essa busca pertinaz possa prejudicar as realizações de ambos.

O Homem procurou sempre escapar ao "destino de ser uma coisa entre as coisas" (LOURENÇO, 2011, p. 74) visto que, através da inteligência, da razão (sensível) e da consciência (e do inconsciente), ele reconhece o mundo como algo que lhe é exterior e tenta compreendê-lo; descobre-se como ser existente colocado no mundo, ser com "consciência de si por correlação com a consciência do que lhe é distinto" (LOIA, 2012, §15) e com a capacidade que a sua condição cognoscente lhe confere de apreender, 
problematizar e interiorizar esse mundo e procurar modificá-lo em seu proveito. Ele atingiu um estádio evolutivo que outros seres (ainda) não alcançaram pois existir não é apenas viver é pensar-se e pensar o mundo. O Homem hodierno possui também no seu inconsciente um manancial imenso de memórias da sua anterioridade, um saber herdado dos seus ancestrais que o vai ajudando a construir a sua própria existência. No entanto, apesar dos enormes progressos culturais da humanidade, feitos em um processo dinâmico de muitos avanços e alguns recuos, o Homem, perante o gigante universal, continua a espantar-se, a apequenar-se, a enovelar-se em dúvidas e a buscar explicações. Mas são precisamente o espanto e a dúvida, de que nos falaram Platão e Descartes, que o impelem no sentido do aperfeiçoamento, sempre na expectativa de atingir uma clarividência cada vez maior que lhe permitirá o total entendimento, buscando as "causas primeiras e as razões últimas" (CARVALHO, 2007, p. 48). Consegui-lo-á? Mas neste hipotético futuro "tempo dos lírios" (?) (FEDELI, 1999, p. 7), o homem como hoje o conhecemos terá deixado de existir para dar lugar não sabemos a que novo modelo de mais ou menos humano, ao homem-Deus ou ao pós-humano (Silva, 2010, p. 14), sendo que este último parece estar já a esboçar-se, segundo alguns teóricos, mercê da nova era global e das novas alquimias técnico-científicas. Enfim, uma diferente antropomorfia poderá surgir no futuro, talvez resultante de um misto de componentes humanos e não-humanos. Mas, esperemos, não seja de matriz eminentemente desumanizada e artificial e que os novos deuses forjados no "gnosticismo tecnológico" (GARCIA, p. 487), alheados da ética humanista sustentada num conjunto de valores nobres, como por exemplo, liberdade, responsabilidade, solidariedade ou compaixão, não façam regredir a espécie humana como o fez o Criador de Lídia Jorge, mas sim fazê-la vencer mais algumas etapas no desbravamento dessa inesgotável senda do conhecimento. Por ora, continuaremos na expetativa desse devir.

Nesta obra Lídia Jorge cativa o leitor para a fruição estética do seu texto, recorrendo a uma narrativa toda percorrida de humor finíssimo, através do qual se vislumbra um toque de ironia que nos propõe a desconstrução de um paradigma de verdades absolutas que a nossa cultura teológica, espiritual ou mítica, de raiz essencialmente judaico-cristã, nos poderá ter inculcado, ainda que apenas no nosso inconsciente coletivo. Parece querer jogar entre uma certa exaltação da capacidade humana, visão prometeica do homem portanto, e a projeção no Criador de sentimentos e limitações caraterísticos do homem. Simulando uma distância abissal entre as criações divina e humana, a autora consegue, com uma delicada habilidade, esbater as diferenças ontológicas entre o
Criador e o Homem, mas não numa aceção cristológica, antes numa aproximação analógica de valoração e crédito na ação humana. A recriação do mundo, porventura de inspiração cabalística, não obstante a grandiosidade do seu aparato, configura um ato não previsto pelo próprio Criador, o que questiona a sua suposta omnisciência e parece prefigurar uma visão fáustica da divindade. Diz o teósofo Baader que é na criação do homem que Deus se manifesta ou seja, só o homem completa Deus (FEDELI, 1999, p. 15), o que numa leitura ateística nos leva a inferir que Deus pode ser uma criação do homem. Poderemos também partilhar da perplexidade de Eduardo Lourenço por não conseguir saber se a ideia de Deus será uma metáfora do Nada, ligando-a à tese de Lídia Jorge para quem - numa intertextualidade pessoana - o nada e o tudo se identificam (PESSOA, 2011, p. 169), "o tudo era igual a nada" (JORGE, 2014, p. 19), mas tendo como adquirido neste dédalo de cogitações, que prosseguiremos sempre com uma latente necessidade de Deus, ainda que saibamos que Ele morreu.

Sob o delicado ponto fino da pureza desta escrita de pendor poético que seduz e enleva, o leitor perscrutando através, e para lá, da aparente simplicidade da imagética da efabulação deste conto, descortina heuristicamente um húmus propiciador de múltiplas reflexões sobre os grandes questionamentos que se colocam ao ser humano e à sua condição existencial e vislumbra também os contornos de uma mensagem de esperança no Homem e nas suas capacidades para prosseguir num ideário de ética humanista.

\section{Maria CARlos Lina de SENA Aldeia CLEPUL/Universidade de Lisboa}

\section{Referências}

CARVALHO, José Maurício de. O homem e a filosofia. Pequenas meditações sobre existência e cultura. Porto Alegre: EDIPUCRS, 2007.

FEDELI, Orlando. Origens do romantismo alemão. Montfort Associação Cultural. Disponível em: <http://www.montfort. org.br/old/index.php?secao $=$ cadernos \&subsecao $=$ religiao \&art igo $=$ romantismo1 $>$. Acesso em: 10 set. 2015.

FREITAS, António de. Os Deuses e a origem do mundo. Antologia de Textos Cosmogónicos. Lisboa: Quetzal Editores, 2015 .

GARCIA, J. L. A plenitude tecnológica em questão. Hermínio Martins e o Experimentum Humanum: Civilização Tecnológica e Condição Humana. Análise Social, v. 203, n. xlvii (2º), p. 483-489, 2012. Dispoível em: <http://analisesocial.ics.ul.pt/ documentos/1341933833G0fZD0bv2Qh85HM2.pdf>. Acesso em: 07 out. 2015.

JORGE, Lídia. O organista/The organist. Edição bilingue. Alfragide: D. Quixote, 2014. 
LOIA, Luís. Miguel Reale. Cultura, Centro de História da Cultura, v. 29, 2012 [online, 31 out. 2013]. Disponível em: $<$ http://cultura.revues.org/1037>. Acesso em: 21 set. 2015. DOI: $10.4000 /$ cultura. 1037

LOURENÇO, Eduardo. Heterodoxias I. Lisboa: Fundação Calouste Gulbenkian, 2011.

PESSOA, Fernando. Livro do desassossego (composto por Bernardo Soares, Ajudante de Guarda-Livros na Cidade de Lisboa). 4. ed. Lisboa: Assírio e Alvim, 2011.
SILVA, Ronaldo Miguel da. Corporeidade e condição do humano no pós-humano: uma abordagem a partir da cristologia. Dissertação (Mestrado) - Pontifícia Universidade Católica do Rio Grande do Sul, Porto Alegre, 2010. Disponível em: $<$ http://repositorio.pucrs.br/dspace/bitstream/10923/5294/1/ 000426569-Texto\%2BCompleto-0.pdf>.Acesso em:09 set. 2015.

Recebido: 23 de março de 2016 Aprovado: 25 de maio de 2016 Contato:mclino@netcabo.pt 